\title{
IMPORTANCE OF CONCRETE IN RCC FRAME STRUCTURE FOR HIGH RISE BUILDINGS AND IMPORTANT INFRASTRUCTURES
}

\author{
Vikram Y Tambvekar ${ }^{1}$, Mrunmayee V Tambvekar $^{2}$ \\ ${ }^{I}$ CMD, Con-Tech CCRC Pvt. Ltd., Concrete R\&D Lab., Digha, Navi Mumbai, Maharastra State -400 708 \\ ${ }^{2}$ Assistant Quality Manager, Con-Tech CCRC Pvt. Ltd., Concrete R\&D Lab, Digha, NaviMumbai, Maharastra 400708
}

\begin{abstract}
"Concrete" is versatile composite material being used in all type of RCC frame structure and for foundation of steel structure frame, machinery foundation, infrastructure like Dams, Bridges, concrete roads etc. In general the project consulting engineers $/$ designers provides structural design details along with grade of concrete as per their design requirements \& concept. Further while actual execution of the project, role of concrete is very important to get desired achievement for serviceability, durability of the structure designed. Concrete has been specified as: i) Normal grade concrete ii) structural grade concrete iii) High performance concrete (HPC).

Water: Water must be checked for pH, chemical contents (chloride \& sulphate), TDS etc., before using for concrete production. Proper mix proportion \& effective use of chemical admixture shall be followed. Strength parameters \& MOE (Modulus of Elasticity) shall be checked to meet requirements as per IS -456-2013.

Durability: Durability of HPC shall be checked for following parameters:

i) RCPT- (Rapid chloride penetration Test as per ASTM-1202-2007

ii) WP (Water Permeability) as per DIN-1048

iii) $M O E$ (Modulus of Elasticity) on concrete - as per IS-516

iv)Water Absorption of Water on concrete - as per BS -1881-part122-1983
\end{abstract}

Keywords: Concrete, HPC, HSC, Durability, Admixture, Compressive Strength, Reinforcement, Pumpable Concrete, Heat of Hydration, Workability, RCC Structural Design.

\section{INTRODUCTION}

\subsection{Concrete}

It is commonly known that the concrete is a mixture of Natural Fine \& Coarse Aggregates with cement and water in proper proportionate quantities, where cement water paste acts as a binding material. It is very essential to consider the importance of all the ingredients with which the concrete is being produced as a composite material. As the properties of the ingredients changes, it tends to change the resultant properties as fresh and hardened concrete significantly.

\subsection{RCC Frame Structure}

In RCC Frame Structure Designs, the respective designer assumes a desired grade of concrete as 'fck' as per respective code of practice (IS/ BS/ ASTM/ EN, etc.) and based on this value the Reinforced Concrete Member is designed. For any construction activity, be it Steel Structure/ Timber Structure/ RCC, Concrete is an essential element in construction activities. For RCC foundation of High Rise Structures, we generally provide Pile Foundation or Raft Foundation and the commonly M-30 Grade of concrete is used to avoid micro cracks developed due to heat of hydration that takes place in high volume of concrete.

\subsection{Heat of Hydration In Concrete}

For HVC (High Volume Concrete), it is generally advised to use maximum amount of Fly Ash (FA) \& GGBS or SCM (Supplementary Cementitious Material) to avoid heat of hydration due to OPC content in high volume of concrete. It is recommended to monitor the temperature development in HVC of Raft Foundation at respective level to assess and to control the temperature so as to avoid micro cracks.

\subsection{Desired Strenght of Concrete}

We express prominently that as for a high rise or any other structure, structural design is important, it is equally important to use concrete either fully or partially i.e. for steel structure - only for foundation \& slabs, etc. It is very important to note that in any type of RCC Frame Structure, the RCC component is nearly $45-50 \%$ including the elevation elements. For high rise buildings, normal grade of concrete used between M40 to M80 (excluding for the raft/ pile foundation provided and use of M30 grade of concrete is recommended).

\subsection{High Performance Concrete (HPC)}

The importance related with following points come in force as specifically mandatory so as to achieve durability in concrete directly and serviceability of the entire structure - 'fck' desired strength of concrete at $28 / 45 / 60$ or 90 days (for M-70 \&M-80 and above)as per requirement of 
project

- Satisfactory value of MoE (Modulus of Elasticity) as per IS-456-2013

- RCPT Values ( Rapid Chloride Permeability test) as per ASTM-1202-2007

- WP values (Water Permeability) as per DIN-1048 - Water Absorption values as per BS-1881-122 It is important to note that the columns for any high rise structures are designed with higher grade of concrete as it requires to take higher compressive strength \& bending moments due to heavy structural load/ wind pressure/ elevational elements load, earthquake \& fire loading.etc.

For satisfying the HPC desired value of 'fck' and durability, the proportion of ingredients is very important with use of right admixtures. All fine and coarse aggregates should satisfy the requirement as per IS-383-2011 and more important that CRF more finer (above $15 \%$ on $75 \mu$ sieve) shall be avoided or shall be used in limited proportion, not more than $30-40 \%$ to avoid drying shrinkage cracks in harden concrete. Concrete specification for general structure - M20 to M40. For high rise structures - Grade of concrete M40 to M80 known as HPC. (M-50 to M80 grade of concrete is known as HPC as it satisfy the durability requirements).

Most important to be note that use of only $10 \mathrm{~mm}$ (MSA) with fine aggregates is more beneficial to design HPC with packing density method as it reduces the voids in fresh concrete.OPC fresh stock of OPC shall be used \& checked for NC as well as for strength gain as per IS 4031. SCM FA/ GGBS/ Alcofine/ SF shall be checked for CR/PR as per IS 4031 to satisfy the performance with OPC before using in large production of concrete.

\subsection{WATER}

\subsection{Testing of Water}

Water must be tested \& checked for all parameters as per IS 456-2013, before taking trials at batching plant or at project Lab to avoid further complications arises due to water content in concrete. Water must be checked for $\mathrm{pH}$, Chloride \& sulphate parameters at all the stages of concrete production or period as project runs in longer time period and sources of water gets change or quality of construction water may change.

\subsection{Use of Bore or Well Water}

Bore well water is mandatory to check for $\mathrm{pH}$, Chloride \& Sulphate as it source from ground water table. $\mathrm{pH}$ up to 6 to 8 is acceptable as per IS 456-2013.Municipal water or any potable water can be directly used for concrete production.

\section{CHEMICALADMIXTURE}

\subsection{SNF Based Admixture}

For concrete up to M-40 SNF base admixture is advisable for obtaining better workability with retarder as per site demand.

\subsection{PC Based Admixture}

$\mathrm{PC}$ based admixture is advisable for concrete above M-45 to M-80 \& more with VMA as per site /project requirement.

\subsection{Admixture Dosage}

Use of PC based admixture with retarder shall not exceed more than $1.5 \%$ as it may delay in final setting of concrete and strength gain may be disturbed/ delayed which will result in adverse effects on the structural frame. Lower W/B ratio $(0.20$ to 0.28$)$ to satisfy the "fck" value which also satisfies the durability aspects as there is good amount of cementitious material content in HPC concrete.

\section{DURABILITY}

To satisfy the 'Durability Aspect' in higher grade of concrete, use of SCM is widely followed as it results to be more beneficiary. As a part of higher grade concrete or HPC, the following proportion was used by M/s Gammon India Ltd ${ }^{[3]}$ at South Mumbai (Project: Nathani Heights) proposed 80 storeyed commercial \& residential Building and all the durability tests were carried out at Con-Tech CCRC Pvt Ltd [4] Concrete Laboratory at Digha, NaviMumbai.

Table 1: Proportion for Mix Design M80 - Supplied by M/s ACC Limited. (RMX Division, Mumbai)\& M/s Ultra-Tech Cement Ltd. (RMC Unit- Mumbai) respectively.

\begin{tabular}{|l|r|r|c|}
\hline \multicolumn{1}{|c|}{ Ingredient } & \multicolumn{4}{c|}{ Quantity per Cubic meter } \\
\hline $\begin{array}{c}\text { Proportion for Mix Design Grade M80 } \\
\text { Supplied by - }\end{array}$ & $\begin{array}{c}\text { M/s ACC Ltd. } \\
\text { RMX Division }\end{array}$ & $\begin{array}{c}\text { M/s UltraTech Cement } \\
\text { Ltd }^{\left[{ }^{[2]}\right]} \text { Unit-RMC }\end{array}$ & $\begin{array}{c}\text { Unit of } \\
\text { Measurement }\end{array}$ \\
\hline Cement OPC & 490 & 300 & $\mathrm{~kg}$ \\
\hline Flyash & 140 & 60 & $\mathrm{~kg}$ \\
\hline GGBS & - & 240 & $\mathrm{~kg}$ \\
\hline Alcofine & 70 & 45 & $\mathrm{~kg}$ \\
\hline CRF (Manufactured Sand) & 709 & 830 & $\mathrm{~kg}$ \\
\hline 20mm Aggregates & 302 & 0 & $\mathrm{~kg}$ \\
\hline 10mm Aggregates & 640 & 930 & $\mathrm{~kg}$ \\
\hline Water & 140 & 140 & $\mathrm{~kg}$ \\
\hline Chemical Admixture (PC Base) & 7 & 7 & $\mathrm{~kg}$ \\
\hline Plastic Density & $\mathbf{2 4 9 8 . 0 0}$ & $\mathbf{2 5 5 2 . 0 0}$ & \\
\hline W/B Ratio & 0.21 & 0.217 & \\
\hline
\end{tabular}


Table 2:RCPT Results as per ASTM - C - 1202 - 2007

\begin{tabular}{|c|c|c|}
\hline $\begin{array}{l}\text { TEST Results for } \\
\text { Grade M80 } \\
\text { concrete Supplied }\end{array}$ & $\underset{\text { Ltd. }}{\text { By }}{ }^{[1]}$ ACC & $\begin{array}{c}\text { By M/s } \\
\text { UTCL }^{[2]}\end{array}$ \\
\hline Date of Casting & $10 / 12 / 2013$ & $23 / 05 / 2013$ \\
\hline Date of Testing & $10 / 03 / 2014$ & $29 / 08 / 2013$ \\
\hline Age in days & 90 & 98 \\
\hline \multirow{3}{*}{$\begin{array}{l}\text { Test Results in } \\
\text { Coulombs }\end{array}$} & 512 & 512 \\
\hline & 530 & 530 \\
\hline & 549 & 549 \\
\hline Remark & Satisfactory & Satisfactory \\
\hline
\end{tabular}

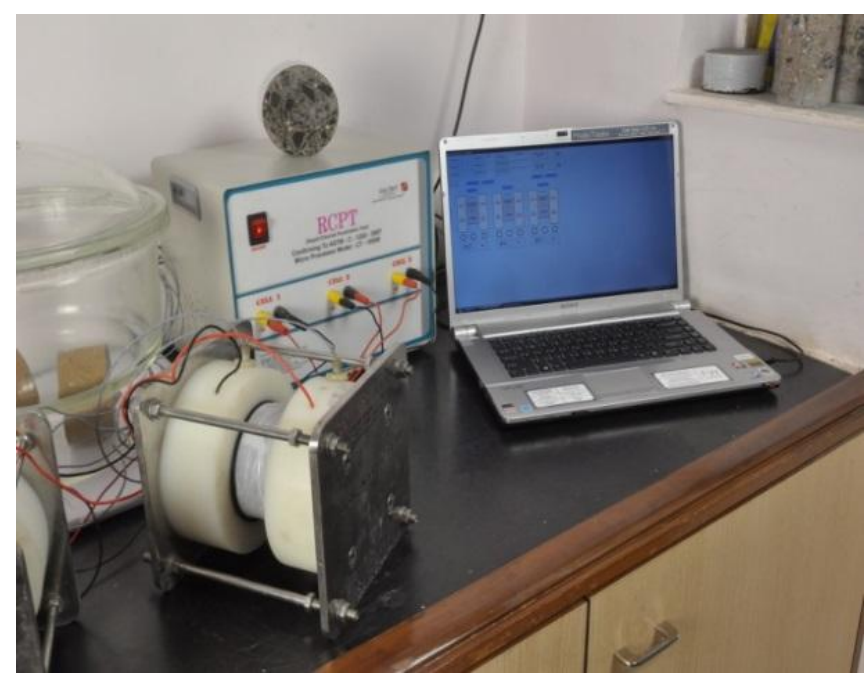

RCPT system as per ASTM - C - $1202-2007$

Table 3: TEST RESULTS of Water permeability as per DIN -1048

\begin{tabular}{|l|c|c|}
\hline $\begin{array}{c}\text { TEST Results for } \\
\text { Grade M80 concrete } \\
\text { Supplied }\end{array}$ & $\begin{array}{c}\text { By M/s ACC } \\
\text { Ltd. }^{[1]}\end{array}$ & $\begin{array}{l}\text { By M/s } \\
\text { UTCL }^{[2]}\end{array}$ \\
\hline Date of Casting & $24 / 04 / 2013$ & $22 / 01 / 2013$ \\
\hline Date of Testing & $19 / 06 / 2013$ & $23 / 03 / 2013$ \\
\hline Age in days & 56 & 60 \\
\hline \multirow{2}{*}{ Test Results in mm } & 11 & 9 \\
\cline { 2 - 4 } & 10 & 7 \\
\hline Remark & Satisfactory & Satisfactory \\
\hline
\end{tabular}

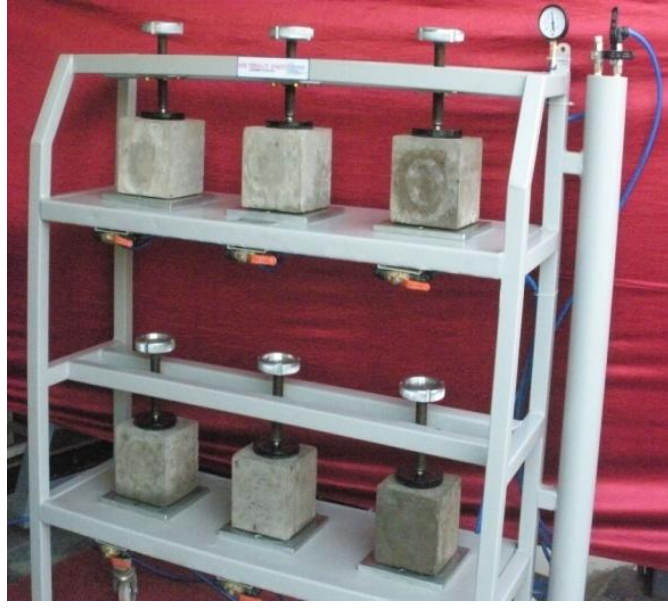

Water permeability test system as per DIN -1048

Table 4:Splitting Tensile Strength of Cylindrical Concrete Specimens

(I) TEST Results for concrete Grade M80 Supplied by M/sUTCL ${ }^{[2]}$

\begin{tabular}{|c|c|c|c|c|}
\hline Date of Casting & Date of testing & Age in days & $\begin{array}{c}\text { Test Results } \\
\text { in N/mm }\end{array}$ & Remark \\
\hline 01-Feb-2013 & 29-Mar-2013 & 56 & 6.61 & Satisfactory \\
\hline 01-Feb-2013 & 29-Mar-2013 & 56 & 4.50 & Satisfactory \\
\hline 01-Feb-2013 & 29-Mar-2013 & 56 & 5.55 & Satisfactory \\
\hline
\end{tabular}

(II) TEST Results for concrete Grade M80 Supplied by M/s ACC Ltd. ${ }^{[1]}$

\begin{tabular}{|c|c|c|c|c|}
\hline Date of Casting & Date of testing & Age in days & $\begin{array}{c}\text { Test Results } \\
\text { in N/mm }\end{array}$ & Remark \\
\hline 22/Jan/2013 & 19/Mar/2013 & 56 & 5.38 & Satisfactory \\
\hline 22/Jan/2013 & 19/Mar/2013 & 56 & 5.02 & Satisfactory \\
\hline 22/Jan/2013 & 19/Mar/2013 & 56 & 5.74 & Satisfactory \\
\hline
\end{tabular}


Table 5:Modulus of Elasticity ['E'-Value] as per ASTM-C-469-02

TEST Results for concrete Grade M80 Supplied by M/s UTCL ${ }^{[2]}$

\begin{tabular}{|c|c|c|c|c|c|}
\hline Sample No & Date of Casting & Date of testing & $\begin{array}{c}\text { Age in } \\
\text { days }\end{array}$ & $\begin{array}{c}\text { Test Results } \\
\text { in GPa }\end{array}$ & Remark \\
\hline Cylinder - 1 & 08-Aug-2014 & 22-Nov-2014 & 106 & 53.25 & Satisfactory \\
\hline Cylinder - 2 & 08-Aug-2014 & 22-Nov-2014 & 106 & 49.86 & Satisfactory \\
\hline Cylinder - 3 & 08-Aug-2014 & 22-Nov-2014 & 106 & 51.26 & Satisfactory \\
\hline
\end{tabular}
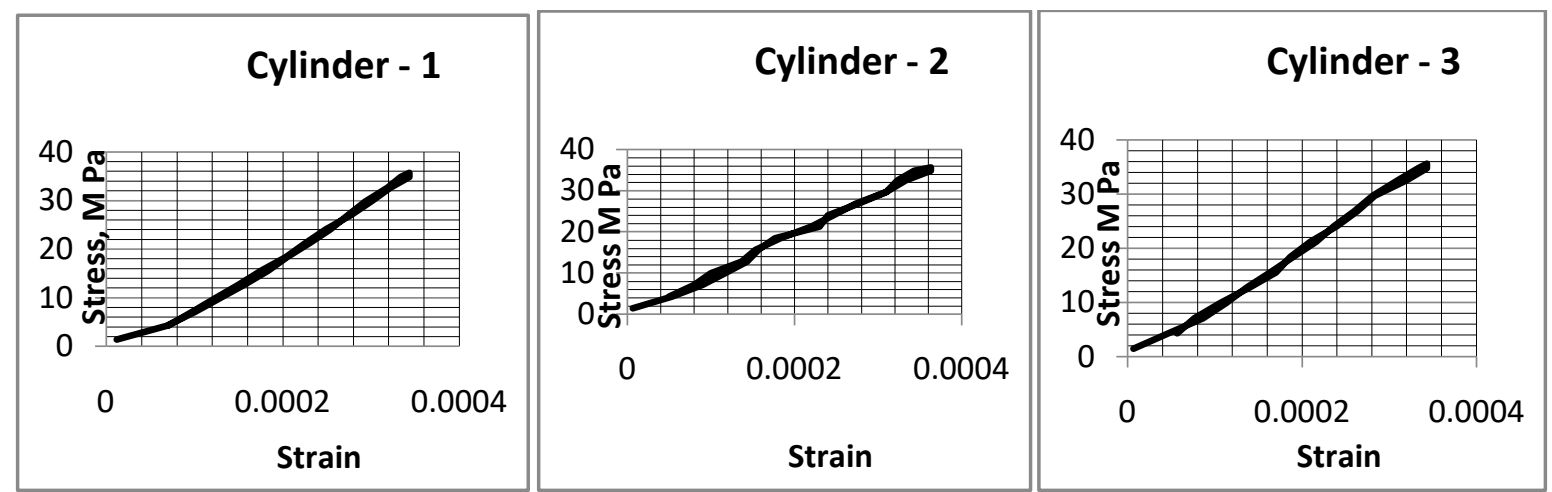

Graphs showing the Stress/ Strain Curve

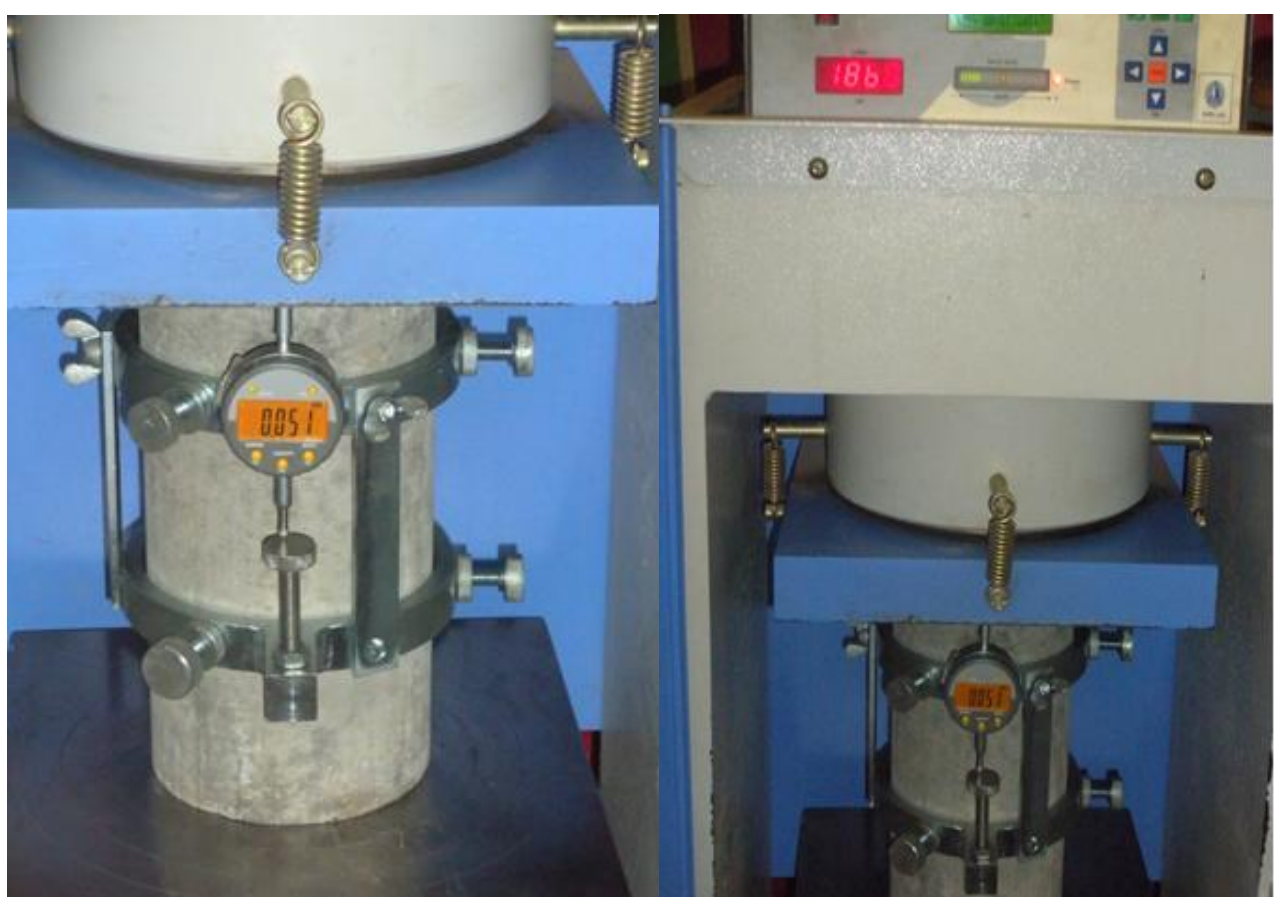

Modulus of Elasticity ['E'-Value] as per ASTM-C-469-02 under process

Table 6: Modulus of Elasticity ['E'-Value] as per ASTM-C-469-02

TEST Results for concrete Grade M80 Supplied by M/s ACC Ltd. ${ }^{[1]}$

\begin{tabular}{|c|c|c|c|c|c|}
\hline Sample No & $\begin{array}{c}\text { Date of } \\
\text { Casting }\end{array}$ & Date of testing & Age & $\begin{array}{c}\text { Test Results in } \\
\text { GPa }\end{array}$ & Remark \\
\hline Cylinder -1 & $21 /$ Oct/2014 & $19 / \mathrm{Jan} / 2015$ & 90 & 47.40 & Satisfactory \\
\hline Cylinder -2 & $21 /$ Oct/2014 & $19 / \mathrm{Jan} / 2015$ & 90 & 52.27 & Satisfactory \\
\hline Cylinder -3 & $21 /$ Oct/2014 & $19 / \mathrm{Jan} / 2015$ & 90 & 53.36 & Satisfactory \\
\hline
\end{tabular}




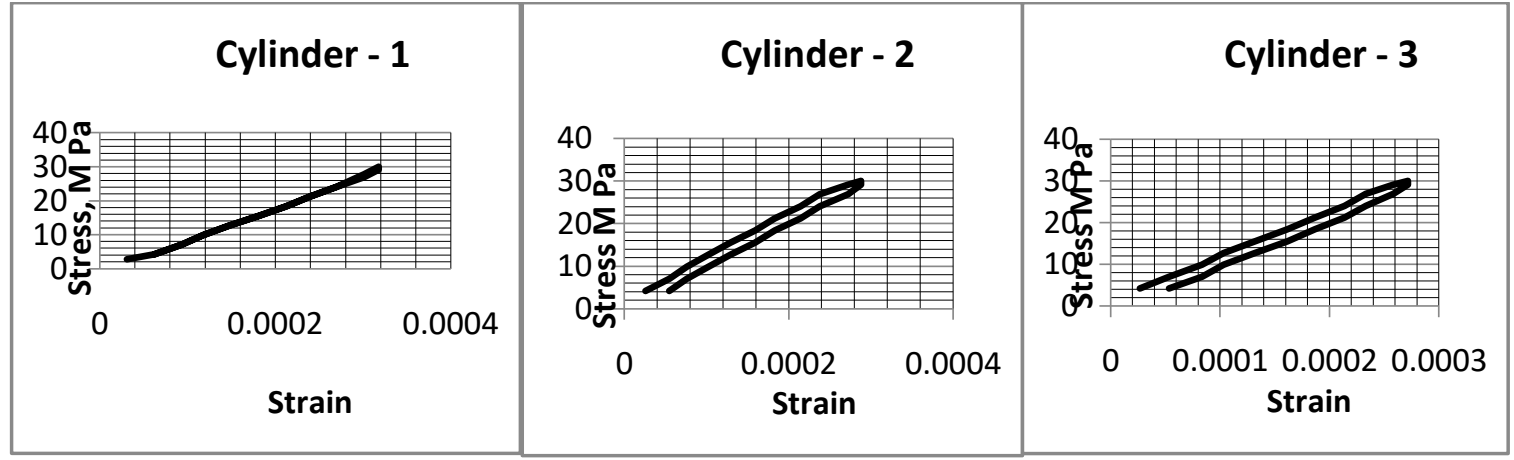

From durability point of view, all above result values were found satisfactory and were approved by the project structural consultant. RCPT is more important criteria and vigorous durability test method for HPC used world-wide (as per ASTM - 1202).

\section{PUMPABLE CONCRETE}

\subsection{Work Ability For Pumping}

Pumpable concrete for high rise structure is also very important criteria, where concrete of higher grade being produced and need to pump up to desired level of the structure for concreting of the RCC columns \& slabs. It is recommended that $10 \mathrm{~mm}$ coarse aggregates (MSA) with preferably river sand (Natural fine aggregates) or manufactured sand with perfect size \& shape to meet IS383-2011 requirements (i.e. Zone II \&III) shall be used to get good quality of pump able concrete.

Most important to be note that use of only $10 \mathrm{~mm}$ (MSA) down aggregateswith fine aggregates is more beneficial to produce as HPC, as it reduces the voids in fresh concrete which help to increase compressive strength \& satisfy other durability parameters due to addition of more cementitious material in fresh concrete.

\section{CONCLUSION}

\subsection{Material Analysis \& Propotioning}

It is very important to assess all the necessary properties (physical \& chemical) of all ingredients of concrete as per relevant code of practice. Cement, Fly Ash, Alcofine, Silica Fume, Chemical admixture, fine \& coarse aggregates, water, etc. and to use in proper proportion to achieve desired strength \& other parameters.

\subsection{Water For Curing}

Curing period \&curing water is one factor that cannot be ignored as it helps to develop the strength of concrete. Under-cured concrete equals to lack of strength which directly affects the durability of any structure or its component.

\subsection{Durability Testing On Harden Concrete}

E-value is more important to high rise structure \& infrastructure like Bridges, Pre-Stressed Girders, etc. RCPT values are assessed to satisfy against the environmental attack on concrete provided for High Rise Structures or Infrastructures like Bridges, Highways, etc. Effective use of SCM can reduce RCPT values significantly which shall help to improve the durability of the structure.

\section{REFERENCES}

[1].Data of HPC design Test results is courtesy from M/s ACC LTD (RMX Division, Mumbai). [2].Data of HPC design Test results is courtesy of M/s UltraTech Cement Ltd (RMC unit, Mumbai). [3].HPC (M-80) was used for Nathani Height Project at South Mumbai by M/s Gammon India Ltd. (Contractor). [4].Testingof HPC (M-80) was carried out at M/s Con-Tech CCRC Pvt. Ltd., Navi Mumbai.

\section{BIOGRAPHIES}

Mr. Vikram Y Tambvekar, a Civil Engineer from VJTI, Mumbai is practising as Professional Structural Engineer in field since last 35 years in various states of India and 15 years as Concrete Consultant who also owns a R\&D Concrete Laboratory inNavi Mumbai. He has been providing Technical Services to various Govt. \& Private Sector Projects nationwide.

Ms. Mrunmayee V Tambvekar holds B.E. (Civil) from SavitribaiPhule Pune University,Maharastra state and working with Con-Tech CCRC Pvt. Ltd. as Assistant quality Manager since 2015. 